\title{
SELETIVIDADE PENAL VERSUS PRINCÍPIO DA DIGNIDADE HUMANA
}

\author{
PENAL SELECTIVTTY VERSUS PRINCIPLE OF HUMAN \\ DIGNITY
}

\author{
Alexandre Luiz. Alves de Oliveira1 \\ $\mathrm{PUC} / \mathrm{MG}$ \\ Lucas de Alvarenga Gontijo2 \\ $\mathrm{PUC} / \mathrm{MG}$
}

\begin{abstract}
Resumo
O presente trabalho almeja realizar uma breve análise do sistema penal brasileiro a observar dois aspectos: o direito penal democrático e a seletividade da aplicação da lei penal. O exercício do poder estatal realiza-se por intermédio do controle social que objetiva determinar os comportamentos dos cidadãos. Dentre as diversas formas de controle social destaca-se o sistema penal devido ao seu alto grau de coerção. O direito penal e os demais instrumentos do sistema penal são tão drásticos que a intensidade como o Estado os utiliza chega, inclusive, a caracterizar o próprio Estado. Desta forma, o texto procura ressaltar a relação entre o indivíduo e o Estado e, ademais, constatar que não é suficiente somente um direito penal democrático para a construção de um Estado Democrático de Direito se sua aplicação for seletiva, isto é, direcionada a atingir apenas algumas parcelas da população, excluindo-se de sua incidência outras.

Palavras-chave

Controle Social. Direito Penal. Seletividade do sistema penal. Teoria do Reconhecimento. Estado Democrático de Direito.
\end{abstract}

\section{Abstract}

The present work aims to make a brief analysis of the Brazilian penal system to observe two aspects: democratic criminal law and selectivity of criminal law enforcement. The exercise of state power is carried out through social control that aims to determine the behavior of citizens. Among the various forms of social control, the penal system stands out due to its high degree of coercion. Criminal law and the other instruments of the penal system are so drastic that the intensity as the state uses them, even characterizes the state itself. In this way, the text seeks to emphasize the relationship between the individual and the State and, in

\footnotetext{
${ }^{1}$ Bacharel em direito pela PUC/Minas, especialista em filosofia pela UFMG, mestre em direito ambiental e desenvolvimento sustentável pela ESDHC e doutorando em direito público pela PUC/Minas. Advogado e professor.

${ }^{2}$ Mestre e doutor em Filosofia do Direito pela UFMG. Professor da graduação e do programa de pós- graduação em direito stricto sensu da PUC/Minas. Professor titular de Filosofia do Direito da Faculdade de Direito Milton Campos. Consultor do Marzinetti, Mendonça, Bedetti Mayrink \& Gontijo Advogados Associados.
} 
addition, to verify that it is not enough only a democratic criminal law for the construction of a Democratic State of Right if its application is selective, that is, directed to achieve only a few portions of the population, excluding their other incidence.

\section{keywords}

Social Control. Criminal Law. Selectivity of the penal system. Theory of Recognition. Democratic state.

\section{A TENSÃO ENTRE PODER COERCITIVO ESTATAL E DIREITO PENAL DEMOCRÁTICO.}

Não é mais possível se falar em natureza humana dentro do espectro epistemológico da contemporaneidade, entretanto é observável que quase a totalidade dos seres humanos vivem em sociedade. A reunião em agrupamentos potencializa a sobrevivência humana ao permitir a especialização das suas atividades laborais. Esta especialização provoca uma dependência inexorável devido ao alto grau da distribuição de tarefas. Desta forma, inimaginável é pensar o homem em sua complexidade contemporânea fora da sociedade.

Dentre as várias formas de associações que os humanos contemporâneos integram, uma é predominante: o Estado. Assim, a sociedade política é uma relação de poder organizada entre governantes e governados. Este poder de comando, que impõe obediência, utiliza-se do controle social como forma de consecução de seus fins que podem ser legítimos ou não a depender da justificação racional norteadora da própria intervenção do Estado. O controle social pode ser instrumentalizado de várias formas. Interessa aqui observar o sistema penal. O sistema penal constitui-se de conjunto de agências que versam sobre a questão criminal. Partindo-se de uma concepção ampla, envolve desde a criação da norma incriminadora até a efetivação da mesma.

Desta forma, o sistema penal abrange grande campo de atividades. Neste presente artigo procurar-se-á analisar, preliminarmente, as relações entre o indivíduo e o Estado a dar ênfase ao direito penal em um Estado Democrático de Direito. Para um sistema penal democrático o ponto inicial de partida é o que se denomina direito penal democrático.

Observa-se, paradoxalmente, que não é suficiente para um sistema penal democrático um direito penal democrático. É imperativo que esse 
observe, também, uma aplicação não seletiva. Esta aplicação não seletiva não corresponde à ideia de uma aplicação total do direito penal para todos os casos, o que é obviamente impossível. Almeja-se, com essa expressão, que o direito penal não seja utilizado pelas autoridades penais como instrumento de coação de apenas uma parcela da população frente à outra. Tanto o direito penal quanto a persecução penal devem seguir os ditames de um Estado Democrático de Direito se são de fato legítimos. Existe uma necessária relação de complementação entre ambos.

Observa-se, por fim, que a estratégica metodológica para a construção deste artigo foram a metodologia revisional crítica somando-se o método inferencialista. Servem, principalmente, como alicerces da construção deste trabalho os textos de Cláudio Brandão e Eugenio Zaffaroni. Em outras palavras, o artigo se alinha à perspectivada escola mineira de direito penal da PUC/Minas, pois tem o conceito de dignidade humana como premissa de todas as inferências que seguem.

\section{SOCIEDADE E CONTROLE SOCIAL}

Observa-se que desde os tempos mais remotos, ganhando ênfase nos últimos séculos, o ser humano se reúne em agrupamentos ou sociedades com as mais diversas finalidades. O total isolamento de pessoas ou grupos é pouco funcional podendo ser considerado uma excentricidade, ainda mais após a revolução industrial e a consequente diversificação do trabalho. "No mundo atual, praticamente não existe isolamento absoluto. Raros são os grupos humanos que não mantém, mesmo que esporadicamente, contatos com outros grupos ou indivíduos, encontramos, isto sim, variações no grau de isolamento"3, arremata Eva Maria Lakatos.

Se no passado, a reunião entre os indivíduos já era importante para a sobrevivência dos mesmos, hoje, a interação é praticamente imprescindível para a subsistência. Inequívoco é que a vida social possibilita o desenvolvimento das aptidões materiais e cognitivas, por suas características interativas, de aprendizado partilhado.

Importante salientar, desde já, que nem todos os conjuntos de indivíduos podem ser denominados sociedades. O termo sociedade 
compreende a reunião de pessoas de forma estável e perene que objetivam atingir um "fim/objetivo" comum. Assim, como bem dispõe Darcy Azambuja, "uma multidão, a plateia de um teatro, etc. não são sociedades, pois, ainda, que se lhes reconheça um efêmero objetivo comum, não têm, no entanto, organização, nem são permanentes" ". Exige-se, de tal maneira, uma ordenação estável do grupo com intuito conhecido e desejado pelos componentes. A pessoa inserida numa sociedade passa por um processo de socialização ${ }^{5}$. Com este processo, que surge desde o nascimento e vai até a morte, o indivíduo interioriza elementos culturais da sociedade, adaptandose ao espaço social. Desta forma, por meio da socialização, os membros da sociedade adquirem e reproduzem os valores intrínsecos da mesma. Portanto, Lakatos assim se expressou:

O processo de socialização, isto é, da aquisição de "maneiras de pensar, de agir, de sentir" do grupo, inicia-se a partir do nascimento e continua ao longo da vida. Durante a infância e adolescência, este processo é mais intenso, depois continua através do primeiro emprego, da participação na vida política, no casamento, na paternidade e até idade bem avançada. Em todos os momentos da vida, a socialização é necessária para orientar as ações dos indivíduos, integrando-os nos grupos, através da aprendizagem, das normas e valores neles vigentes. ${ }^{6}$

${ }^{4}$ AZAMBUJA, Darcy. Teoria geral do Estado. 40. ed. São Paulo: Globo, 2000, p.2.

${ }^{5}$ Destaca-se a passagem de Pedro Scuro Neto, ao dispor que: "A essência desses processos - socialização- é a virtude, exclusivamente humana, de usar símbolos e linguagens ao mesmo tempo para a transmissão de cultura. Nesta acepção, socialização, em sociologia, é diferente da noção utilizada, por exemplo, pelos economistas quando falam da propriedade privada em propriedade estatal, ou do senso comum, no sentido de interação social numa atmosfera agradável, de camaradagem, cooperação e simpatia. Esses significados não têm a ver com a concepção dada pela antropologia cultural e a teoria da educação: constituição do ambiente no qual o indivíduo aprende um idioma, regras de pensamento conceitual, um pouco de história da comunidade da qual faz parte, princípios básicos de sobrevivência e de desenvolvimento individual, assim como regras morais para se relacionar com os outros membros da comunidade." (SCURO NETO, Pedro. Sociologia ativa e didática: um convite ao estudo da ciência do mundo moderno. São Paulo: Saraiva, 2004, p.176.). ${ }^{6}$ LAKATOS, Eva Maria. Sociologia Geral. 4. ed. São Paulo: Atlas, 1982, p.85. 
Uma vez ocorrido o processo de socialização de um indivíduo perante uma sociedade, com a absorção dos valores centrais do grupo, Lakatos relata que surgem os comportamentos de "desvio" e "conformidade"7. A conformidade é ação dirigida para a norma estabelecida. A conformidade é a sujeição do agir do indivíduo a expectativa de comportamento da sociedade. Por sua vez, o desvio ${ }^{8}$ é o agir disfuncional, ou seja, o comportamento que foge do padrão estabelecido. $\mathrm{O}$ desvio é a não interiorização ou a não aceitação dos valores da sociedade e a consequente violação da norma. Quando ocorre o desvio, instala-se um processo de sanções “cuja função é punir a infração, impedir futuros desvios ou alterar as condições que originam o comportamento desviado. Este processo constitui o controle social"'. Ou ainda, no mesmo sentido, vale a reprodução do levado de Scuro:

De certo modo, as condutas desviantes contribuem, até mais que os comportamentos certos, para o sucesso e a vitalidade dos sistemas sociais, ajudando a tornar mais claras as regras que definem a consciência coletiva, que determinam o que é bom senso e explicam a própria sociedade. Desvios de conduta levam as normas sociais ao extremo, bem além dos limites permitidos, obrigando os grupos e os indivíduos a se definir constantemente, fazendo-os sentir a necessidade de regulamentar, ou seja, de especificar direitos e obrigações, de estabelecer o que pode ser feito e o que não pode. ${ }^{10}$

${ }^{7}$ LAKATOS, Eva Maria. Sociologia Geral. 4. ed. São Paulo: Atlas, 1982, p.184.

${ }^{8} \mathrm{O}$ desvio, segundo Anthony Giddens, pode ser compreendido como: "O desvio pode ser definido como uma desconformidade em relação a um determinado conjunto de normas que são aceitas por um número significativo de pessoas em uma comunidade ou sociedade. Nenhuma sociedade pode ser dividida de maneira simples entre aqueles que se desviam das normas e aquelas que se conformam com elas. A maioria das pessoas, em certas ocasiões, transgride regras de comportamento aceitas. Geralmente, seguimos as normas sociais, porque, como resultado da socialização, estamos acostumados a fazê-lo." (GIDDENS, Anthony. Sociologia. Tradução: Ronaldo Cataldo. 6. ed. Porto Alegre: Penso, 2012, p.664). 'LAKATOS, Eva Maria. Sociologia Geral. 4. ed. São Paulo: Atlas, 1982, p.185.

${ }^{10}$ SCURO NETO, Pedro. Sociologia ativa e didática: um convite ao estudo da ciência do mundo moderno. São Paulo: Saraiva, 2004, p.192. 
Essas teorias tem raízes na teoria do reconhecimento hegeliana, sobretudo se apanhadas nas teses do jovem Hegel, em sua fase de Jena. Georg Mead apresenta, sob a égide da psicologia social, uma síntese do pensamento hegeliano ao afirmar que toda ação humana deve ser entendida dentro de uma rede de expectativas, mais precisamente em expectativas de expectativas. O humano age dentro de um leque de possibilidades expectáveis, sendo que o desvio da ação ou das ações tidas como corretas configura o que se chama de frustração. A frustração implica, a seu turno, uma reelaboração prática a procura de reestabelecer a expectativa rompida, isto é, um tipo de repressão inibidora da conduta que reafirme a expectativa desejada pelos membros de uma comunidade. ${ }^{11}$

Logo, segundo a perspectiva de George Mead, os seres humanos agem conforme sabem que os demais membros de uma interação social esperam que ele aja. $\mathrm{O}$ agir faz parte de como o agente vê a si mesmo como membro de uma comunidade. $\mathrm{O}$ infrator, isto é, aquele que age conforme a conduta proibida não se reconhece como membro comprometido com aquela comunidade, a que causa uma frustação. A punição à frustração é uma reafirmação da exigência da conduta expectável.

O poder para punir é a questão específica do direito penal. Zaffaroni e Pierangeli destacam que toda sociedade apresenta como característica uma estrutura de poder ${ }^{12}$. Ao se analisar qualquer sociedade, constata-se que existe um grupo que comanda e o outro que obedece. Verifica-se, assim, um círculo de indivíduos que detém o poder (ou são próximos) e outro ou outros agrupamentos que se encontram alijados deste poder. A forma de exercer este poder e exigir o comportamento desejado, evitando-se o desvio, se faz através do instituto do controle social.

Pois bem, o controle social pode ser definido como conjunto de medidas utilizadas pelos detentores do poder de uma sociedade com o escopo de que as condutas dos indivíduos se adéquem a determinado padrão expectável. Por meio de sanções positivas ou negativas, o controle social reforça os valores almejados e desencoraja a prática dos

${ }^{11}$ Cf. MEAD, George Herbert. Mind, Self and Society: from the standpoint of a social behaviorist, The University of Chicago Press, 1992.

${ }^{12}$ ZAFFARONI, Eugenio Raúl; PIERANGELI, José Henrique. Manual de direito penal brasileiro: parte geral. 10. ed. rev. atual. São Paulo: Revista dos Tribunais, 2013, p.62. 
comportamentos desviantes. O sistema procura, então, evitar frustrações ou, também, reafirmar a validade das regras todas as vezes que houver uma frustração.

Eva Maria Lakatos, ao analisar a obra Meios de Controle Social de Frederick E. Lumley,destaca que existiriam duas categorias principais de controle do social:

1)a que se apóia na força física e a 2) a que se apóia em símbolos. A primeira, apesar de indispensável, não pode por si só, manter a ordem social, surgindo a necessidade de controles sociais fundamentados em símbolos. Estes são de dois tipos: os que se destinam a provocar nos indivíduos o mesmo tipo de resposta e a dirigir seu comportamento para determinados rumos considerados desejáveis (educação, incentivo, elogio, uso da persuasão e lisonja) e os mecanismos cujo objetivo é a restrição e a repressão (ordens, ameaças e punições, propaganda, crítica, sátira e o ridículo; boatos e falatórios). ${ }^{13}$

Zaffaroni e Pierangeli relatam que o controle social poderia ser dividido, também, em duas classes: controle social difuso e o controle social institucionalizado ${ }^{14}$. Seriam exemplos de controle social difuso os meios de comunicação em massa, como a televisão e o rádio, a família, a moda, os preconceitos. Lado outro, poder-se-ia citar como meios de controle social institucionalizados, as escolas, as universidades, os tribunais, etc. Dentre os meios institucionalizados ressalte-se o sistema penal.

Verifica-se, assim, que o sistema penal engloba a atividade de diversos atores sociais. A polícia, o promotor, o juiz, a sociedade civil e o legislador atuam, conjuntamente, dentro deste sistema. Sem negar a grande importância dos outros envolvidos, destaca-se, primeiramente, a importância da lei penal (atividade legiferante) para o controle social ${ }^{15}$.

${ }^{13}$ LAKATOS, Eva Maria. Sociologia Geral. 4. ed. São Paulo: Atlas, 1982, p.193. ${ }_{14}$ ZAFFARONI, Eugenio Raúl; PIERANGELI, José Henrique. Manual de direito penal brasileiro: parte geral. 10. ed. rev. atual. São Paulo: Revista dos Tribunais, 2013, p.69.

15 Conforme Zaffaroni e Pierangeli: O sistema penal é o "controle social punitivo institucionalizado, que na prática abarca a partir de quando se detecta ou supõe detectar-se uma suspeita de delito até que se impõe e executa uma pena, pressupondo uma atividade 
Tendo-se em vista que o direito penal fixa o âmbito da criminalização, imprescindível observar alguns requisitos (princípios) para um direito penal legítimo dentro de um Estado Democrático de Direito.

\section{DIREITO PENAL SOB OS CRIVOS DO ESTADO DEMOCRÁTICO DE DIREITO}

No decorrer de sua existência, o ser humano integra outras sociedades, objetivando atender suas potencialidades/finalidades econômicas, sociais e cognitivas, como por exemplo, quando se associa a uma empresa ou um grêmio social. Dentre as várias opções associativas disponíveis, uma se tornou cada vez mais presente e inexpugnável à vida moderna que envolve o indivíduo. É a sociedade política ${ }^{16}$ institucionalizada por meio da superestrutura Estado. ${ }^{17}$

O Estado é, de certa maneira, a mais abrangente ordenação jurídica e política de uma sociedade. Para a organização desta comunidade estabelece determinações ou normas, ou seja, o que convenciona por direito. O Estado, desta forma, é, para os indivíduos e para as sociedades, um poder de comando que determina as condutas permitidas ou proibidas. $\mathrm{O}$ aspecto coativo e a generalidade caracterizam as normas por ele editadas vinculando todos os que habitam o seu território. ${ }^{18}$

normativa que cria a lei que institucionaliza o procedimento, a atuação dos funcionários e define os casos e condições para esta atuação. Esta é a idéia geral do "sistema penal" em um sentido limitado, englobando a atividade do legislador, do público, da polícia, dos juízes, promotores e funcionários e da execução penal. (ZAFFARONI, Eugenio Raúl; PIERANGELI, José Henrique. Manual de direito penal brasileiro: parte geral. 10. ed. rev. atual. São Paulo: Revista dos Tribunais, 2013, p.70).

${ }_{16}$ Para Jorge Miranda existem duas perspectivas para a relação entre Estado e sociedade política: "O Estado é político, mas todo político é estadual? Para alguns a resposta é positiva: Estado e sociedade política identificam-se e aquele é tomado como fenômeno humano permanente e universal. Para outros, o Estado é uma espécie (a mais importante, mas uma entre várias espécies) de sociedade política. Ainda doutro prisma, o problema não se põe, ou por não se lidar com o conceito de Estado ou por se reduzir o Estado ao nome convencionalmente dado a qualquer sociedade política." (MIRANDA, Jorge. Teoria do Estado e da Constituição. Rio de Janeiro: Forense, 2002, p.19).

${ }^{17}$ AZAMBUJA, Darcy. Teoria geral do Estado. 40. ed. São Paulo: Globo, 2000, p.2. ${ }^{18}$ AZAMBUJA, Darcy. Teoria geral do Estado. 40. ed. São Paulo: Globo, 2000, p.5. 
Interessante, também, salientar que o vocábulo "direito", como qualquer substantivo abstrato, não possui sentido unívoco ${ }^{19}$. O termo pode ser empregado com diversas significações a depender do contexto, como se bem sabe por compreender as dimensões pragmatistas do direito ${ }^{20}$. Com efeito, no âmbito jurídico, adotando-se diferentes metodologias ou inclinações filosóficas, encontram-se sentidos discordantes para o termo.

Dentro da locução "direito penal", a palavra "direito" pode ser entendida como um conjunto de normas de conduta social, impostas coercitivamente pelo Estado. Compreendido a palavra "direito" dentro da ideia de ordenamento jurídico, o que se pode depreender pela adjetivação pelo termo "penal"? Hans Wezel define o direito penal como a parte do ordenamento jurídico que determina as ações de natureza criminal vinculando a elas uma pena ou uma medida de segurança. "El derecho penal es la parte del ordenamiento jurídico que determina lãs acciones de naturalez acriminal y las vincula con una pena o medida de seguridad" ${ }^{21} \mathrm{O}$ objetivo deste ramo do direito, ao menos hipoteticamente, seria a proteção dos valores fundamentais para a vida da sociedade."Esmisión del derecho penal amparar los valores elementales de la vida de la comunidad". ${ }^{22}$

Santiago Mir Puig, em seu livro Introdução as bases do Direito Penal, observando as lições de Von Liszt, apresenta uma conceituação bastante próxima: o Direito Penal é um conjunto de normas jurídicas que têm como pressuposto o delito associando a este como consequência jurídica as penas

19 "A palavra "direito" é, assim, tida por uns como análoga, ou seja, seus sentidos guardam certa relação entre si; mas é apontada por outros como vaga e ambígua, visto que suas significações, não são sempre claras, ou geram dúvida legítima e insolúvel ou, até mesmo, apresenta-se de forma paradoxal e contraditória" (NUNES, Rizzatto. Manual de introdução ao estudo do direito. 10. ed. São Paulo: Saraiva, 2011, p. 74).

${ }^{20}$ GONTIJO, Lucas de Alvarenga de. Ensaio sobre teorias da argumentação sob os crivos da racionalidade pragmática, da guinada linguística e do discurso do estado democrático de direito. (in): OMMATI, MAGALHÃES, OLIVEIRA e GONTIJO (org.), Teorias da Argumentação Jurídica e Estado Democrático de Direito, $4^{\circ}$ volume da coleção teoria crítica do direito, Rio de Janeiro: Lumen Juris, 2017.

${ }^{21}$ WELZEL, Hans. Derecho penal: parte general. Buenos Aires: Roque de Palma, 1956, p.1.

${ }^{22}$ WELZEL, Hans. Derecho penal: parte general. Buenos Aires: Roque de Palma, 1956, p.1. 
e/ou as medidas de segurança ${ }^{23}$.Cezar Roberto Bitencourt, por sua vez, também, apresenta uma delimitação do conceito nos mesmos termos:

O Direito Penal apresenta-se, por um lado, como um conjunto de normas jurídicas que tem por objeto a determinação de infrações de natureza penal e suas sanções correspondentes - penas e medida de segurança. Por outro lado, apresenta-se como um conjunto de valorações e princípios que orientam a própria aplicação e interpretação das normas penais. Esse conjunto de normas, valorações e princípios, devidamente sistematizados, tem a finalidade de tornar possível a convivência humana, ganhando aplicação prática nos casos ocorrentes, observando rigorosos princípios de justiça. ${ }^{24}$

Verifica-se, diante destas conceituações, que o principal elemento diferenciador do direito penal de outros ramos do direito é a natureza de sua sanção, ou seja, a pena (medida de segurança). Dentre as diversas sanções existentes no ordenamento jurídico, a pena é a mais grave. Por este motivo, não é raro o Direito Penal ganhar a alcunha de o "ramo mais forte do direito".

Falar em pena ${ }^{25}$ é falar de violência, em sofrimento. O Direito Penal é a forma de proteção de bens jurídicos ${ }^{26}$ mais severa do ordenamento

23 “ "...]el derecho penal es el conjunto de normas jurídicas que al delito como presupuesto asocian penas y (o) medidas de seguridad como consecuencia jurídica" PUIG, Santiago Mir. Introducción a las bases delderecho penal. 2. ed. Buenos Aires: B de F, 2003, p.8). ${ }^{24}$ BITENCOURT, Cezar Roberto. Tratado de direito penal: parte geral. 20. ed. rev. e ampl. e atual. São Paulo: Saraiva, 2014, p.36.

${ }^{25}$ De acordo com Cláudio Brandão a origem do termo pena: "Para alguns, a pena vem do latim poena,que significa sofrimento, de outro lado, há os que acham que a palavra pena provém do grego ponos, que significa dor; ainda os que identificam no sânscrito punya, que significa purificação (de um mal), a origem da palavra pena". (BRANDÃO, Cláudio. Curso de direito penal: parte geral. 2. ed. Rio de Janeiro: Forense, 2010, p.315).

${ }^{26}$ Segundo Mir Puig: "concepto de bien jurídico capaz de limitar legislador no debe buscarse em la realidad naturalística ni en la valoración subjetivo-moral (no realizable mediante la coacción externa) sino en El terreno de lo social. Bienes jurídicos son las condiciones necesarias, según la observación empírica, de um correcto funcionamiento de los sistemas sociales. Pero para evitar una concepción poço respetuosa para conel individuo, que lo contemple solo desde la perspectiva de suutilidad social, convienerequerir que tales condiciones se traduzcan en concretas posibilidades de participación del individuo em los 
jurídico, pois comina como sanção de uma infração penal uma limitação/privação de direitos fundamentais. Quando uma pena é aplicada invariavelmente ocorre uma diminuição ou perda de bens jurídicos do infrator, aliás, um dos fins da pena é a reprovação do mal causado.Paradoxalmente, ao mal causado pelo crime, aplica-se o mal da pena $^{27}$.

O Estado combate violência com violência. Interessante notar que no mundo fenomênico tanto a conduta do delinquente como a resposta estatal são violências. O homicida e o carrasco ceifam a vida alheia. $\mathrm{O}$ sequestrador e o policial limitam a liberdade de locomoção. O furto e a multa diminuem o patrimônio. Percebe-se que, ontologicamente, representam o mesmo fato, ou seja, limitação/privação de bens jurídicos.

Constata-se, desta forma, que pena é violência, contudo, institucionalizada. A violência da pena é uma reação a uma ação delituosa anteriormente cometida. Desta maneira, a pena seria legítima, pois é uma resposta estatal a uma agressão vedada pelo ordenamento jurídico. Cláudio Brandão, assim, sintetiza:

É por isso que Carnelutti já afirmava que, na relação custo e benefício, crime e pena são a mesma coisa, são formas de produzir um dano. Portanto, a pena, assim como o crime, também é uma forma de manifestação da violência. Todavia, a pena é uma reação, que somente se imputa em face da realização prévia de um crime; por isso o Estado, através do Direito Penal, a qualifica como legítima, já que ela será uma conseqüência em face do cometimento de uma violência prévia - que é o crime - por parte do agente que a sofre. ${ }^{28}$

procesos de interacción y comunicación social. (PUIG, Santiago Mir. Introducción a las bases delderecho penal. 2. ed. Buenos Aires: B de F, 2003, p.124).

${ }^{27} \mathrm{La}$ pena es um mal que se dicta contra el autor por el hecho culpable. Se basa sobre el postulado de una retribución justa, que "cada uno sufralo que sus hechos valen" (KANT), vale decir, sobre el postulado de la armonía entre merecimiento de felicidad y felicidad, merecimiento de pena y sufrimiento de pena". (WELZEL, Hans. Derecho penal: parte general. Buenos Aires: Roque de Palma, 1956, p.234).

${ }^{28}$ BRANDÃO, Cláudio. Curso de direito penal: parte geral. 2. ed. Rio de Janeiro: Forense, 2010, p.9. 
Diante da gravidade de sua sanção, portanto, o Direito Penal deve ser a ultimaratio. Somente quando o bem jurídico tiver importância fundamental para a sociedade e outros ramos do direito forem insuficientes na sua tutela deve-se utilizar deste ramo do direito para exercer o controle social.No âmbito penal, o princípio da dignidade da pessoa humana determinará a aplicação de um jus puniendi vinculado a princípios importantes ${ }^{29} \mathrm{como}$, por exemplo, o da legalidade, o da ofensividade, da culpabilidade, da responsabilidade individual, da individualização, etc. Desta forma, somente quando atende ao cânone maior da Constituição, dignidade da pessoa humana (e seus desdobramentos), pode-se falar de um direito penal legítimo dentro de um Estado Democrático de Direito.

O Estado Democrático de Direito é, em sua constituição teórica, uma fórmula política jurídica estatal fundada na autonomia da pessoa humana, sendo que sua finalidade se esgota na própria proteção e potencialização do cidadão.

\section{A SELETIVIDADE DO SISTEMA PENAL}

Observa-se que da análise da natureza do direito penal material pode-se detectar a faceta política do Estado. Um Estado que edifica seu direito penal sob o alicerce do princípio da dignidade da pessoa humana (e seus desdobramentos, principalmente a legalidade) tem, a princípio, uma natureza democrática, contudo, pode-se dizer que este fato é um indicativo e não uma relação de necessidade.

Oportuno lembrar que o direito penal fixa o âmbito da criminalização. $O$ legislador estabelece os padrões de comportamento aceitáveis e as sanções cabíveis em caso de desvio. Verifica-se, todavia, que ocorre uma supervalorização da atividade seletiva do poder legiferante, pois

\footnotetext{
29“"Em la actualidad no cabe discusión alguna respecto de la vinculación de la ley penal conestos principios superiores. Ella está lejos de constituir una opción metodológica libre del legislador o del intérprete de la ley. A la inversa: la validez de los textos y de las interpretaciones de los mismos, dependerá de su compatibilidad conestos principios superiores. De esta manera, la interpretación de la ley penal depende de la interpretación de la Constitución.” (BACIGALUPO, Enrique. Derecho penal y el estado de derecho. Santiago: Jurídica de Chile, 2005, p.104).
} 
o sistema penal é bem mais amplo. Diversos setores (polícia, ministério público, etc.) irão participar na aplicação da lei penal e, consequentemente, interferir na punibilidade ou não do indivíduo. Desta forma, o direito penal democrático $^{30}$ é um dos elementos essenciais para um sistema penal democrático, mas não somente o único.

A lei penal fixa um âmbito dentro do qual o sistema penal de que faz parte pode selecionar e criminalizar pessoas. Sem embargo, o sistema penal ultrapassa o marco penal deste âmbito, na realidade social, o que faz com outros pretextos que pretendem ser "não penais" (contravencionais, averiguação de antecedentes, etc.), e também se abstém de abarcá-lo (não criminaliza a todos os que realizam as condutas ameaçadas penalmente). Ou seja, a lei penal deve determinar um âmbito orientador, mas o sistema penal atua em grande parte com uma orientação que é própria e diferente, excedendo a orientação em um sentido e, em outro, desinteressando-se do espaço demarcado, reprimindo o que o direito penal não o autoriza e deixando de reprimir o que o direito penal lhe ordena. ${ }^{31}$

Como dispõem Zaffaronie Pierangeli ${ }^{32}$, em qualquer sistema penal existem alguns segmentos na aplicação da lei. Estes segmentos, hodiernamente, são praticamente três: o policial, o judicial e o executivo.

${ }^{30}$ Partindo-se de uma idéia um tanto utópica da possibilidade de construção de um direito penal não vinculado aos centros de poder, principalmente econômico. Nota-se, entretanto, que o que se verifica, não tão raramente, é um Direito Penal que tutela interesses de classe, étnicos, de gênero, etc... Nenhum direito penal é neutro ao valor podendo ser mais ou menos democrático, mais ou menos preconceituoso, mais ou menos segregador. "Amalgamado com o conceito normativista e liberal do poder e do político, radica-se, a sua vez, na manualística dogmática do Direito penal, um conceito consensual da sociedade concebida como realidade atomizada, ficticiamente conformada por sujeito de direitos livres e iguais [...]. Nesta sociedade não se visualizam conflitos de classe, étnicos, raciais, assimetrias, subordinações ou discriminações [...].(ANDRADE, Vera Regina Pereira de. Pelas mãos da criminologia: o controle penal para além da (des)ilusão. Rio de Janeiro: Revan, 2012, p.236).

31ZAFFARONI, Eugenio Raúl; PIERANGELI, José Henrique. Manual de direito penal brasileiro: parte geral. 10. ed. rev. atual. São Paulo: Revista dos Tribunais, 2013, p.80. 32ZAFFARONI, Eugenio Raúl; PIERANGELI, José Henrique. Manual de direito penal brasileiro: parte geral. 10. ed. rev. atual. São Paulo: Revista dos Tribunais, 2013, p.71. 
Estes três componentes do sistema penal institucionalizado (realmente punitivo) não atuam propriamente em etapas estanques, pois o que se verifica, na realidade, é o predomínio de um destes segmentos em um determinado momento da persecução criminal. "Assim, o judicial pode controlar a execução, o executivo ter a seu cargo a custódia do preso durante o processo, o policial ocupar-se das transferências de presos condenados ou informar acerca da conduta do livramento condicional". ${ }^{33}$ Nota-se, então, que a prevenção/investigação, o processo (conhecimento) e a execução da pena não são atributos únicos e exclusivos de apenas um segmento.

O sistema penal é o conjunto de agências que lidam com a questão criminal. Algumas são exclusivamente penais (polícia, serviço penitenciário, tribunais penais, órgãos políticos de interior, segurança, inteligência, etc.) outros participam do poder punitivo, porém suas funções são mais amplas como: as agências políticas (executivo, legislativo); as agências de reprodução ideológica (universidades, faculdades, academias); os cooperadores internacionais (agências internacionais que financiam projetos); os organismos internacionais que organizam programas, conferências, seminários, etc. (ONU, OEA, etc); e o grande aparato de propagada das agências de comunicação em massa. ${ }^{34}$

Eugenio Raúl Zaffaroni observa que estes segmentos do sistema penal, por mais estranho ao senso comum que possa parecer, não convergem para uma única função/interesse. Cada um destes segmentos, de acordo com seu setor, tem seu próprio interesse principal e secundário (que pode ser reconhecido explicitamente ou não). As cúpulas policiais desejam aumentar seu poder e sua arbitrariedade frente aos outros órgãos do governo; as cúpulas penitenciárias almejam rigor nas prisões, pois os motins causam escândalos; os tribunais querem estabilidade, poucos controles e recursos. Se é verdade que todos participam do poder punitivo

33ZAFFARONI, Eugenio Raúl; PIERANGELI, José Henrique. Manual de direito penal brasileiro: parte geral. 10. ed. rev. atual. São Paulo: Revista dos Tribunais, 2013, p.80.

${ }^{34}$ ZAFFARONI, Eugenio Raúl. Manual de Derecho Penal: parte general/ Eugenio Raúl Zaffaroni, Alejandro Slokar y Alejandro Alagia. 1. ed. Buenos Aires: Ediar, 2005, p.10. 
repressivo (na aplicação do jus puniendi), não é falacioso que possuem alguns interesses peculiares ou ideologias. ${ }^{35}$

O que se deseja frisar aqui é que o crime é uma construção onde participam diversos atores sociais. Desde o legislador, que elege as condutas e penas, até o carcereiro que cumpre o alvará de soltura do apenado que cumpriu sua sanção. E, ademais, as funções realmente exercidas por estes atores podem ser legítimas ou não tendo em vista os interesses envolvidos. Neste instante é importante relatar que o sistema penal exerce uma criminalização primária e uma secundária. Entende-se por criminalização primária a formulação legal de uma conduta proibida sob a ameaça de imposição de uma sanção. É um mandamento dirigido a toda a sociedade que, no entanto, em termos práticos, não é de possível concretização (nem todos que furtam são apenados, nem todos os que tiram xérox sofrem condenação, etc.). Por sua vez, a criminalização secundária é a ação punitiva exercida sobre um indivíduo concreto. Como não é possível efetivar toda a criminalização primária, somente algumas pessoas irão verdadeiramente responder pelo delito (criminalização secundária). É na criminalização secundária que se verifica a seletividade do sistema penal feita pelos seus segmentos. É neste instante de seletividade que os interesses dos segmentos do sistema penal (legítimos ou não) ganham relevância.

Desta forma, a questão da seletividade surge da observação de que todos nós praticamos condutas delituosas e não somente uma parte da sociedade. Todos somos criminosos e vítimas. Observa-se, assim, a seletividade do sistema penal quando apenas uma categoria de indivíduos é criminalizada. A criminalização secundária de só uma parcela da população é a evidenciação da seletividade perversa do sistema. ${ }^{36}$

Ora, se a conduta criminal é majoritária e ubíqua e a clientela do sistema penal é composta, regularmente e em todos os lugares do mundo, por homens adultos jovens, pertencentes aos mais baixos estratos sociais e em grande medida não

35ZAFFARONI, Eugenio Raúl. Manual de Derecho Penal: parte general/ Eugenio Raúl Zaffaroni, Alejandro Slokar y Alejandro Alagia. 1. ed. Buenos Aires: Ediar, 2005.

${ }^{36}$ ANDRADE, Vera Regina Pereira de. Pelas mãos da criminologia: o controle penal para além da (des)ilusão. Rio de Janeiro: Revan, 2012, p.138. 
brancos, isto significa que a impunidade e a criminalização (e também a vitimação) são orientadas pela seleção desigual de pessoas, de acordo com uma fortíssima estereotipia presente no senso comum e nos operadores do controle penal, e não pela incriminação igualitária de condutas, como programa o discurso jurídico-penal. ${ }^{37}$

Esta percepção acima apontada por Vera Regina Pereira de Andrade é confirmada pelos dados do Infopen levantados até julho de 2014 :

A prevalência de baixa escolaridade segue uma constante entre os presos, o que indica que esta população já era vulnerável ou marginalizada antes de serem presas. O estudo aponta que dois em cada três detentos são negros, e metade da população prisional não freqüentou ou possui ensino fundamental incompleto. Além disso, cerca de $56 \%$ deles são jovens, com 18 a 29 anos. ${ }^{38}$

A função declarada do sistema penal, que é o combate à criminalidade, perde-se quando há uma persecução penal dirigida pelos interesses escusos (conscientes ou não) dos segmentos penais. De nada adianta um Direito Penal construído dentro dos ditames da dignidade da pessoa humana se a sua aplicação for direcionada. Se todos nós cometemos delitos, indaga-se, por que somente uma parcela da população é submetida ao sistema penal?

Quem poderia dizer que nunca cometeu um crime: um pequeno furto, um atestado médico falso, um jeitinho para pagar menos imposto de renda (ou seja, sonegação fiscal), uma propina para o guarda, ou, pelo menos, um adultério...? Fosse efetivamente cumprida a lei penal, para que se punissem todos os casos em que se desse sua violação, praticamente não haveria ninguém que não fosse várias vezes processado e punido, tendo-se que propor como

\footnotetext{
${ }^{37}$ ANDRADE, Vera Regina Pereira de. Pelas mãos da criminologia: o controle penal para além da (des)ilusão. Rio de Janeiro: Revan, 2012, p.138.

38 Dados do Infopen citados na Carta Capital. https://www.cartacapital.com.br/sociedade/brasil-possui-a-quarta-maior-populacaoprisional-do-mundo-7555.html. acesso: 10 de jul. de 2017.
} 
conseqüência, tão lógica quanto absurda, a transformação da sociedade em um imenso presídio, o que também não funcionaria, pois dificilmente sobraria alguém para julgar, ou para exercer a função de carcereiro. ${ }^{39}$

Percebe-se a gravidade do problema. Pode-se afirmar que já é extremamente difícil a construção de um Direito Penal plenamente respeitador dos Direitos Humanos. Não raras vezes, o direito não representa os interesses democráticos, mas constitui-se instrumento de controle dos meros detentores do poder. Entretanto, partindo-se da hipótese de um Direito Penal construído democraticamente, depara-se com esta outra questão emblemática: a aplicabilidade seletiva. Seletividade que dependerá de interesses e ideologias dos envolvidos.

Mas, mais do que a ineficácia e a impossibilidade de cumprimento do fim anunciado, a atuação excepcional, baseada na seleção arbitrária de um ou outro autor de condutas definidas como crimes, para que, sendo preso, processado ou condenado, seja identificado e, assim, passe a desempenhar o papel de criminoso, enquanto os demais seguem desempenhando seus papéis de cidadãos respeitadores das leis, demonstra a injustiça que é da essência do sistema penal. ${ }^{40}$

Um exemplo paradigmático da seletividade do sistema penal foi noticiado ${ }^{41}$ recentemente em Mato Grosso do Sul. Breno Fernando Solon Borges, de 37 anos, foi preso com R\$129 kg de maconha em Água Clara, Mato Grosso do Sul. Além da droga, a polícia encontrou 199 munições de fuzil e uma pistola. Verificou-se, que mesmo antes de ser preso por estes delitos, Breno já era investigado pela Polícia Federal sobre um possível plano de resgate de detentos do presídio de Três Lagoas e de integrar a

\footnotetext{
${ }^{39}$ KARAM, Maria Lúcia. De crimes, penas e fantasias. Niterói: Luam Ed.. 1993, p.202. ${ }^{40}$ KARAM, Maria Lúcia. De crimes, penas e fantasias. Niterói: Luam Ed.. 1993, p.203. ${ }^{41}$ Reportagem do site G1: http://g1.globo.com/fantastico/noticia/2017/07/juiz-diz-quefilho-de-desembargadora-nao-deveria-ter-sido-liberado.html acesso: 31 de jul. de 2017.
} 
respectiva organização criminosa. A princípio estes delitos em nada se diferenciam frente a tantos outros cometidos atualmente salvo uma singularidade: Breno é filho da desembargadora Tânia Garcia (TJ-MS).

Como noticiado no programa Fantástico da Rede Globo, Breno foi beneficiado por uma decisão do desembargador Ruy Celso Florence para encaminhamento para uma clínica de tratamento psiquiátrico. O que causou estranheza, nesta decisão, foi a sua não conformidade com decisões anteriores de acordo como o levantamento realizado pela reportagem. Em outros casos onde presos detinham uma quantidade de droga extremamente menor, o desembargador não tomou a mesma atitude ${ }^{42}$. Além disso, apurouse que o tratamento psiquiátrico poderia ser feito no próprio presídio, que, aliás, era modelo frente aos demais. Não era necessário interná-lo em outro local. Ressalte-se que a crítica aqui não é sobre o encaminhamento dos dependentes químicos ou de quem possua algum distúrbio a um tratamento psiquiátrico adequado, mas quem faz jus a este benefício ou não fora do presídio.

Além desta peculiaridade acima citada e muito mais grave a depender da apuração, foi à atuação direta da mãe de Breno, a desembargadora Tânia Garcia. O juiz da vara de execuções penais Rodrigo Pedrini, em documento encaminhado ao Ministério Público, relata que os habeas corpus concedidos não revogavam um segundo mandado de prisão existente contra Breno e, por isso, este não poderia ser transferido. Afirma, também, que a desembargadora insistiu para a liberação do seu filho e após alguns telefonemas conseguiu seu intento à revelia do juiz da vara de execuções não respeitando, assim, os trâmites legais. O caso encontra-se sob a análise do CNJ diante de tantas "peculiaridades".

Situação que, também, demonstra a seletividade do sistema penal nos é informado por Gustavo Hermont Corrêa em seu livro O Ministério Público sobre o olhar do outro. O autor traz um capítulo sobre a omissão do Ministério Público na investigação contra policiais no Estado do Rio de Janeiro. "Diante de uma estatística avassaladora, o Ministério Público com frequência tem sua atuação comprometida e consentida por distorções

\footnotetext{
${ }^{42}$ A reportagem não deixou claro se os casos analisados também eram de quem apresentava algum distúrbio mental.
} 
graves nos processos de investigação manejados em face de policiais". ${ }^{43}$ Baseando-se em dados levantados pela UFRJ constatou-se 99,2\% de processos arquivados sem investigação. Conclui o pesquisador:

Todavia, diante dos dados levantados pelo Núcleo de Estudos em Cidadania, Conflito e Violência Urbana da UFRJ, percebemos que não adianta sermos mais realistas que o rei, um dos maiores responsáveis pela impunidade dos crimes cometidos pelos militares no Brasil, é o próprio titular da ação penal e um dos responsáveis por conduzir a investigação criminal do país: o Ministério Público! Inacreditáveis 99,2\% de processos arquivados sem investigação! Esses números compõem essa alarmante estatística alusiva a implantação de um sistema próprio de impunidade dos policiais que matam. Uma demonstração clara de um controle externo da polícia pífio, para não se dizer inexistente por parte do Ministério Público. ${ }^{44}$

Não pode deixar de ser mencionado, também, como caso emblemático de seletividade do sistema penal o fato do plenário da Câmara dos Deputados ter negado a autorização para a abertura de processo criminal contra o Presidente Temer. Com base em gravações e na delação premiada dos irmãos Joesley e Wesley Batista, o Procurador-Geral da República, Rodrigo Janot, denunciou o Presidente Michel Temer ao Supremo Tribunal Federal (STF) por crime de corrupção passiva. Além de corrupção passiva, há suspeitas de organização criminosa, lavagem de dinheiro e obstrução à Justiça. As justificativas dos deputados para a não permissão da abertura do processo criminal foram as mais diversas, destacando-se, principalmente, a instabilidade econômica que seria provocada. Interessante notar, entretanto, que por fatos de gravidade imensamente menor não tiveram dúvidas de promover o impeachment da

${ }^{43}$ CORRÊA, GUSTAVO HERMONT. O Ministério Público sobre o olhar do outro: Uma experiência fundada na alteridade de Emmanuel Lévinas. Rio de Janeiro: Lunem Juris, 2016, p.245.

${ }^{44}$ CORREAA, GUSTAVO HERMONT. O Ministério Público sobre o olhar do outro: Uma experiência fundada na alteridade de Emmanuel Lévinas. Rio de Janeiro: Lunem Juris, 2016 , p.247. 
ex- Presidente Dilma. Julgamento para Michel Temer agora somente após a conclusão do mandato.

Percebe-se, assim, a fragilidade do sistema penal, pois não se mostra suficiente uma legislação penal/processual democrática se os operadores do sistema não são imparciais na sua aplicação. Para alguns (que não participam do centro do poder) aplicam a letra "fria" da lei em interpretações vinculadas a um direito penal máximo. Para os membros do seu círculo, ou não aplicam a lei ou até mesmo a burlam utilizando-se dos mais diferentes artifícios.

Constata-se, assim, o duplo nó do sistema penal. Primeiro, a necessidade de o Direito Penal observar os ditames da dignidade da pessoa humana e todos os princípios daí decorrentes. Segundo, a aplicação não preconceituosa (homogênea) do mesmo,o que é dever dos agentes do Estado, pois os interesses envolvidos na aplicabilidade originam-se de ideologias que devem ser afastadas o tanto quanto possível, sobretudo inclinações de cunho pessoal.

Desta forma a lei penal que obedece aos ditames do princípio da dignidade da pessoa humana é o primeiro passo que se mostrará insuficiente sem a participação dos demais envolvidos. Não basta um Direito Penal democrático sem uma persecução penal democrática (processo penal democrático).

\section{CONCLUSÃO}

A seletividade penal se assemelha ao direito penal do inimigo ${ }^{45}$. A escolha de um grupo social a ser punido, mesmo que isso signifique o estrito cumprimento das regras de direito, pode, por motivos de seleção, se transformar no não direito.

${ }^{45}$ JAKOBS, Günther. Direito penal do inimigo, tradução de Gércélia Batista Mendes, Rio de Janeiro: Lumem Juris, 2009. 
Danosa a possibilidade do sistema penal se transformar em um órgão político, a implodir todas as conquistas de direitos da pessoa humana, conquistados desde as revoluções liberais do século XVIII. Superar o Antigo Regime e sepultar o direito penal sem limites custou à humanidade um número razoável de levantes, insurreições e algumas revoluções. Mas é inequívoco que do século XVIII para cá tropeços foram contados e democracias inteiras foram arrastadas à vontade de grupos ou classes sociais que usurparam o poder político, a romper o pacto democrático. O Estado jamais deve ser usado como máquina política, agravando-se imensamente se seu uso for por intermédio do direito penal, o uso da violência estatal.

Dadas estas circunstâncias, se o direito penal pune mais os pobres ou os negros no Brasil, tem-se um sistema de seletividade em ação. Se o Estado pune apenas membros de alguns partidos políticos, tem-se um sistema de seletividade em ação. É preciso lembrar de que o direito à isonomia é uma conquista política travada a altos custos. Eis aí o divisor de águas entre o direito moderno e medievo. A superação do Antigo Regime é uma conquista de cunho francamente iluminista, fundada em conceitos de liberdade, autonomia política. O caráter necessariamente republicano exigido do poder público impõe-lhe limitações em função do respeito absoluto ao princípio da dignidade bumana,ou submissão incondicional do Estado ao princípio da legalidade ${ }^{46}$. A sociedade dos iguais não pode ter outro fundamento senão a autonomia política de cada um de seus membros, inexoravelmente comprometidos em criar as normas que aplicar-se-ão a si mesmos. E como se sabe, a normatividade ${ }^{47}$ é a questão do direito por excelência.

É sabido que o princípio da dignidade da pessoa bumana é uma espécie de princípio guarda-chuva, pois abriga outros direitos fundamentais e humanos, como direito à acusação formal, direito à ampla defesa (sobretudo

46 “[...] O sistema penal tem como partes o Estado e a pessoa humana. Juridicamente, o Princípio da Legalidade se presta para equilibrar o sistema penal, dando ao Estado uma fonte - ainda que limitada - para a emissão de seus comandos e à pessoa humana uma série de garantias, que são decorrentes da significação jurídica desse Princípio." (BRANDÃO, Cláudio. Curso de direito penal: parte geral. 2. ed. Rio de Janeiro: Forense, 2010, p. 57). ${ }^{47}$ Normatividade é a capacidade que as leis têm de se fazer valer. O poder da lei de forçar seu cumprimento. 
direito ao contraditório), direito à publicidade do processo jurídico, direito a previsibilidade das penas no ordenamento jurídico, etc. O conceito matriz de toda teoria do Estado Democrático de Direito é a liberdade, no sentido de conquista da autonomia política. As restrições aos cidadãos devem se ater aos direitos substantivos negativos. Essa máxima se aplica, incondicionalmente, ao direito penal. O princípio da legalidade, arqueado a todo o processo de fundação da modernidade, ${ }^{48}$ está resguardado como clausula pétrea no âmago do texto constitucional brasileiro. Mas é preciso observar como violências simbólicas se reproduzem sem a devida atenção que merecem ${ }^{49}$. Pierre Bourdieunos atenta para essa questão. Os mecanismos de poder simbólico infiltram no quotidiano e se perpetuam em sistemas de comunicação subliminares, atingindo inúmeros plexos discursivos. Até que ponto a sociedade brasileira não se tornou negligente ao passo de conceder anuência tácita à supressão de direitos e garantias individuais a ponto de sombrear diante de um protótipo de Estado Penal? Até que ponto, como conferiu Hannah Arendt à sociedade alemã na década de 1930, a sociedade civil brasileira não fez vista grossa à prática da seletividade penal? ${ }^{50}$

Este artigo se fecha com a esperança de ter conseguido reafirmar, sobretudo em tempos de crise, o dever de se respeitar o devido processo penal democrático. Para além do direito penal, há o sistema penal, como nos ensina Zaffaroni. Garantir funcionamento do sistema penal democrático é o graal de qualquer sociedade pretensamente democrática. Por fim, encerramos com a inferência de que a democracia é uma conquista de todos os dias.

\section{REFERENCIAS}

ANDRADE, Vera Regina Pereira de. Pelas mãos da criminologia: o controle penal para além da (des)ilusão. Rio de Janeiro: Revan, 2012.

\footnotetext{
${ }^{48}$ Cf. os capítulos 1 e 2 do livro. GONTIJO, Lucas de Alvarenga. Filosofia do direito: metodologia jurídica, teoria da argumentação e guinada linguística-pragmática, Belo Horizonte: Arraes Editores, 2011.

${ }^{49}$ BOURDIEU, Pierre. Langageetpouvoirsymbolique. Paris: ÉditionsFayard, 2001.

50ARENDT, Hannah. As Origens do totalitarismo: Anti-semitismo, imperialismo, totalitarismo. Tradução de Roberto Raposo, título original: The originsoftotalitarianism, São Paulo: Companhia das letras, 1989.
} 
ARENDT, Hannah. As Origens do totalitarismo: Anti-semitismo, imperialismo, totalitarismo. Tradução de Roberto Raposo, título original: The originsoftotalitarianism, São Paulo: Companhia das letras, 1989.

AZAMBUJA, Darcy. Teoria geral do Estado. 40. ed. São Paulo: Globo, 2000.

BACIGALUPO, Enrique. Derecho penal y el estado de derecho. Santiago: Jurídica de Chile, 2005.

BITENCOURT, Cezar Roberto. Tratado de direito penal: parte geral. 20. ed. rev. e ampl. e atual. São Paulo: Saraiva, 2014.

BOURDIEU, Pierre. Langageetpouvoirsymbolique. Paris: ÉditionsFayard, 2001.

BRANDÃO, Cláudio.Curso de direito penal: parte geral. 2. ed. Rio de Janeiro: Forense, 2010.

CORREAA, GUSTAVO HERMONT. O Ministério Público sobre o olhar do outro: Uma experiência fundada na alteridade de Emmanuel Lévinas. Rio de Janeiro: Lunem Juris, 2016.

GIDDENS, Anthony. Sociologia. Tradução: Ronaldo Cataldo. 6. ed. Porto Alegre: Penso, 2012.

GONTIJO, Lucas de Alvarenga de. Ensaio sobre teorias da argumentação sob os crivos da racionalidade pragmática, da guinada linguística e do discurso do estado democrático de direito. (in): OMMATI, MAGALHÃES, OLIVEIRA e GONTIJO (org.), Teorias da Argumentação Jurídica e Estado Democrático de Direito, $4^{\circ}$ volume da coleção teoria crítica do direito, Rio de Janeiro: Lumen Juris, 2017.

GONTIJO, Lucas de Alvarenga. Filosofia do direito: metodologia jurídica, teoria da argumentação e guinada linguística-pragmática, Belo Horizonte: Arraes Editores, 2011.

KARAM, Maria Lúcia. De crimes, penas e fantasias. Niterói: LuamEd, 1993.

JAKOBS, Günther. Direito penal do inimigo, tradução de Gércélia Batista Mendes, Rio de Janeiro: Lumem Juris, 2009.

LAKATOS, Eva Maria. Sociologia Geral. 4. ed. São Paulo: Atlas, 1982. MIRANDA, Jorge. Teoria do Estado e da Constituição. Rio de Janeiro: Forense, 2002. 
NUNES, Rizzatto. Manual de introdução ao estudo do direito. 10. ed. São Paulo: Saraiva, 2011.

PUIG, Santiago Mir. Introducción a las bases delderecho penal. 2. ed. Buenos Aires: B de F, 2003.

SCURO NETO, Pedro. Sociologia ativa e didática: um convite ao estudo da ciência do mundo moderno. São Paulo: Saraiva, 2004.

WELZEL, Hans. Derecho penal: parte general. Buenos Aires: Roque de Palma, 1956.

ZAFFARONI, Eugenio Raúl. Manual de Derecho Penal: parte general/ Eugenio RaúlZaffaroni, Alejandro Slokar y Alejandro Alagia. 1. ed. Buenos Aires: Ediar, 2005.

ZAFFARONI, Eugenio Raúl; PIERANGELI, José Henrique. Manual de direito penal brasileiro: parte geral. 10. ed. rev. atual. São Paulo: Revista dos Tribunais, 2013. 